\title{
Two new species of the genus Panorpa Linnaeus (Mecoptera, Panorpidae) from Yunnan, China
}

\author{
Ji-Shen Wang', Bao-Zhen Hua' \\ I Key Laboratory of Plant Protection Resources and Pest Management, Ministry of Education, Entomological \\ Museum, Northwest A\& F University, Yangling, Shaanxi 712100, China \\ Corresponding author: Bao-Zhen Hua (huabzh@nwafu.edu.cn)
}

\begin{tabular}{c|c|c|c|c|}
\hline Academic editor: B. Price $\mid$ Received 2 January 2016 Accepted 5 April $2016 \mid$ Published 10 May 2016 \\
http://zoobank.org/39F0AB9E-64DE-4DF3-9E94-935A6E8049D6
\end{tabular}

Citation: Wang J-S, Hua B-Z (2016) Two new species of the genus Panorpa Linnaeus (Mecoptera, Panorpidae) from Yunnan, China. ZooKeys 587: 151-162. doi: 10.3897/zookeys.587.7674

\begin{abstract}
Two new scorpionfly species, Panorpa reflexa sp. n. and Panorpa parallela sp. n., are described and illustrated from Yunnan Province, China. Panorpa reflexa can be readily differentiated from its congeners by the 3-shaped parameres in male genitalia. Panorpa parallela is unique for its parallel parameres in male genitalia. The number of Panorpa species is raised to four in Yunnan Province, and to 113 throughout China.
\end{abstract}

\section{Keywords}

Biodiversity, Hengduan Mountains, Mount Daxueshan, scorpionfly, taxonomy

\section{Introduction}

Panorpidae are the largest family in Mecoptera, and currently consist of approximately 400 species in six genera worldwide (Hu et al. 2015). Panorpids are commonly called scorpionflies, because the genitalia of their males are globular and recurved over the back, resembling the tail of a scorpion (Byers and Thornhill 1983; Bicha et al. 2015). Scorpionflies mostly live in humid, high-elevated and vegetation-rich habitats (Byers 
and Thornhill 1983; Byers 2002a). Males of many scorpionflies offer nuptial gifts to the female during courtship and copulation, and use the clamp-like notal organ on the third tergum to seize the anterior edge of the wings of the female (Zhong and Hua 2013a). These insects are frequently considered to represent ideal models for the study of mating systems and behavior in insects (Ma and Hua 2011a; Zhong et al. 2015a). However, the males of Furcatopanorpa longihypovalva (Hua \& Cai, 2009) lack a notal organ, and assume an unusual O-shaped position during copulation (Zhong et al. 2015b).

Panorpa Linnaeus, 1758 is the most speciose genus in Panorpidae, consisting of approximately 252 species worldwide and 111 species in China to date (EsbenPetersen 1921; Carpenter 1945; Byers 1970; 2002b; Chou et al. 1981; Fu and Hua 2009; Zhang and Hua 2012; Zhong and Hua 2013b). Panorpa differs from Neopanorpa Weele, 1909 and Leptopanorpa MacLachlan, 1875 by the vein 1A ending at or beyond the level of the origin of Rs, in addition to genital features (Cheng 1957). Based on morphological and molecular data (Misof et al. 2000; Ma et al. 2011, 2012; Hu et al. 2015), the genus Panorpa has been confirmed to be a paraphyletic group. Recently, three genera have been established from Panorpa Linnaeus: Sinopanorpa Cai \& Hua in Cai et al. 2008 (3 spp.), Furcatopanorpa Ma \& Hua, 2011 (1 sp.) and Dicerapanorpa Zhong \& Hua, 2013 (8 spp.).

Yunnan is a province in southwestern China and well-known for its richness in biodiversity (Yang et al. 2004). Historically, five species of Panorpa were recorded from Yunnan. Recently, Panorpa kimminsi Carpenter, 1948, Panorpa triclada Qian \& Zhou, 2001, and Panorpa tjederi Carpenter, 1938 were transferred to Dicerapanorpa Zhong \& Hua, 2013. Consequently, only two species, Panorpa issikiana Byers, 1970 and Panorpa kunmingensis Fu \& Hua, 2009, remain in the genus Panorpa from Yunnan. In our recent survey in the Mount Daxueshan, the southernmost prolongation of the Hengduan Mountains, numerous scorpionfly specimens were collected and determined to belong to two undescribed species of Panorpa Linnaeus, raising the number of Panorpa species to four in Yunnan Province, and to 113 throughout China.

\section{Material and methods}

Specimens examined in this study were captured with collecting nets and temporarily preserved in $75 \%$ ethanol. After observation and initial measurements, some type materials were pinned as permanent preservation and deposited in the Entomological Museum, Northwest A\&F University, China (NWAU).

Measurements of the right wings of 20 males and 20 females of the two new species were made with a vernier calliper, calculated with Microsoft Excel 2010 and are presented as mean \pm SD (standard deviation). Some genitalia were macerated in $10 \%$ $\mathrm{NaOH}$ solution for 3 minutes and then rinsed with tap water. Photographs were taken with a Nikon D7000 digital camera, and further treated with Adobe Photoshop CS4. Dissections and observations were made under a Nikon SMZ 1500 microscope. The abdominal segments are described as abbreviates, e.g., A1 is the first segment. 


\section{Description}

\section{Panorpa reflexa sp. $\mathrm{n}$.}

http://zoobank.org/3264DA6D-00F6-4302-9AE0-302C058641B1

Figs $1-3,4 \mathrm{~A}$

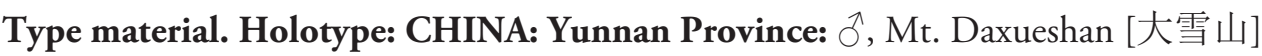
$\left(24^{\circ} 11.27^{\prime} \mathrm{N}, 99^{\circ} 37.35^{\prime} \mathrm{E}\right), 2000 \mathrm{~m}$, Yongde County [永德县], 21 Aug. 2015, leg. JiShen Wang. Paratypes. 31 $\widehat{\gamma} 48$ 우, same data as the holotype, 21-23 Aug. 2015.

Diagnosis. The new species can be recognized by the following features: 1) dorsum of body with one broad pale longitudinal stripe mesally; 2) head yellowish brown with the ocellar triangle and the postvertex black; 3) wings hyaline with a greatly reduced pterostigmal band; 4) hypandrium greatly shortened, with hypovalves only reaching the basal third of the gonocoxites; and 5) parameres 3-shaped.

Description of male. Head. Head mostly yellow. A black pattern on postvertex, transverse, shallowly notched on anterior margin, and laterally adjacent to compound eyes; another black pattern around ocellar triangle, almost pentagonal, with its anterior margin extending to the upper border of the light yellow antennal sockets. Antennal scape brown, pedicel dark brown, flagellum black with 38-42 segments. Rostrum unevenly yellowish brown with genae pale. Maxillary and labial palps yellowish with distal segments darkening toward the apex (Fig. 1C).

Thorax. Pronotum brown, with 6-10 stout setae along its anterior margin. Mesoand metanotum brown with a broad pale longitudinal stripe and a narrow brown mesal line (Fig. 1D). Pleura pale yellow. Legs light brown with coxae pale yellow and distal tarsomeres brown.

Wings. Forewing length $10.40 \pm 0.37 \mathrm{~mm}$, width $2.40 \pm 0.17 \mathrm{~mm}$. Pterostigma light brown with dense microtrichia. Wing membrane hyaline, devoid of markings except the greatly reduced brown pterostigmal band, which forms an irregular spot at vein $R_{1}$ and extending to vein $M_{1}$ as a series of discontinuous spots. Vein $1 \mathrm{~A}$ ending at the hind margin beyond the level of the origin of Rs. Hindwing length $9.47 \pm 0.36$ $\mathrm{mm}$, width $2.28 \pm 0.11 \mathrm{~mm}$, similar to forewings, but with the pterostigmal band more degenerated (Fig. 1A).

Abdomen. Terga I-V brown, with a pale longitudinal mesal stripe connected with the thoracic stripe anteriorly and narrowing posteriorly. Notal organ on the posterior margin of tergum III slightly developed and covering the acute dorsal process of tergum IV (Fig. 1D). Sterna I-V light brown, pleura pale. A6 blackish brown with distal third yellowing gradually, cylindrical, without anal horns. A7 and A8 yellowish orange, with faint brown textures laterally; A7 nearly cylindrical, A8 slightly constricted basally and beveled apically (Fig. 1E).

Male genitalia. Genital bulb yellowish orange, oval, slightly flat in lateral view (Fig. 2). Epandrium (tergum IX) extending beyond the apex of gonocoxite, slightly constricted midway, distal half tapering toward the apex, with a deep U-shaped terminal emargination and forming two parallel digital processes (Fig. 2C). Cerci clavate. Hyp- 


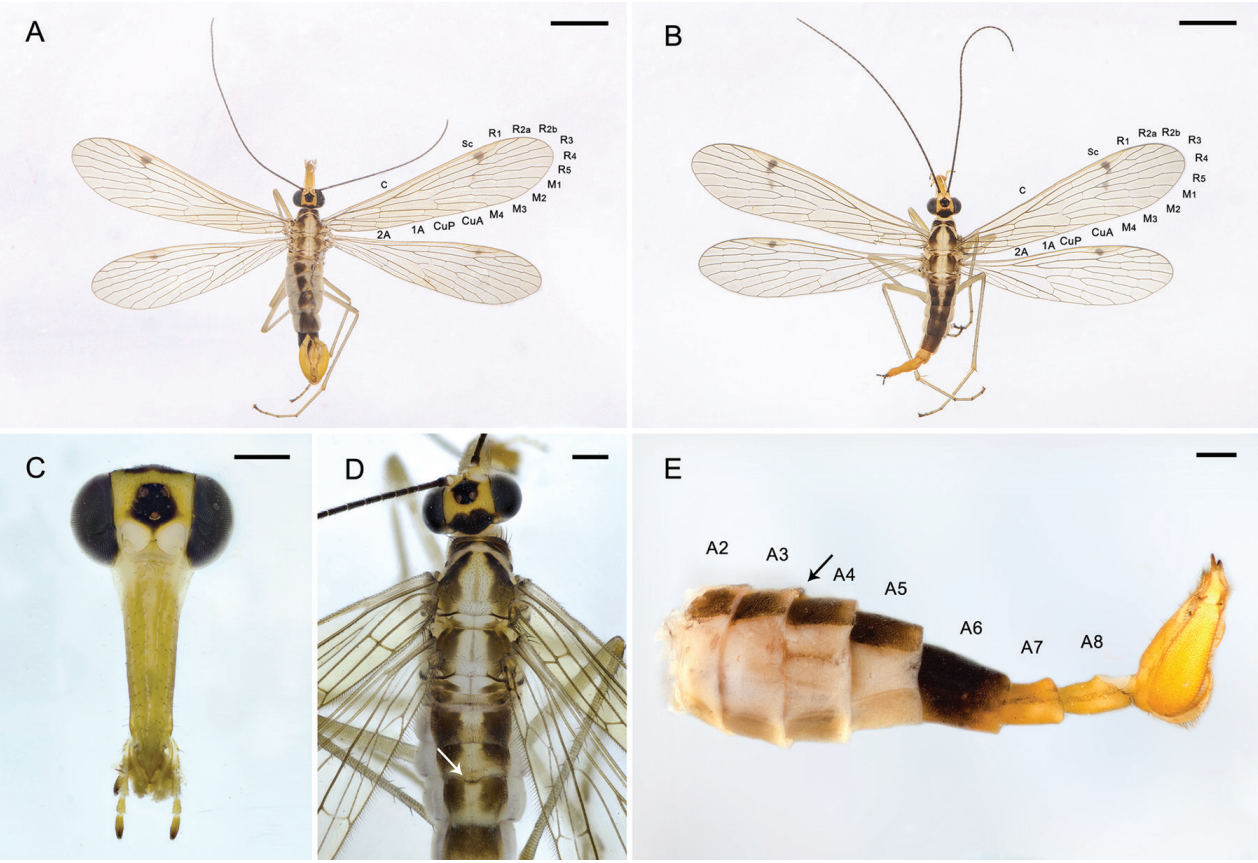

Figure I. Adults of Panorpa reflexa sp. n. A Habitus of male, dorsal view B habitus of female, dorsal view $\mathbf{C}$ head of male with antennae removed, frontal view $\mathbf{D}$ dorsum of male $\mathbf{E}$ abdomen of male, lateral view. Arrows show the notal organ on tergum III. Scale bars: $2.5 \mathrm{~mm}(\mathbf{A}, \mathbf{B}) ; 0.5 \mathrm{~mm}(\mathbf{C}-\mathbf{E})$.

andrium (sternum IX) greatly shortened, extending only to the basal third of gonocoxites, hypovalves bearing long bristles along inner margins (Fig. 2A). Gonostylus shorter than half the length of gonocoxite, outer margin slightly concaved, inner margin with a blunt median tooth and a curved subbasal process (Fig. 2G). Parameres 3-shaped; both arms nearly half the length of aedeagus, with acute tips, and bearing numerous microtrichia along inner margins; anterior arms stretched under hypovalves. (Fig. 2A, $\mathrm{B})$. Ventral valves of aedeagus thick, slightly sclerotized with apexes rounded, bearing numerous soft setae; dorsal valves strongly sclerotized, with many marginal spines and prominent, flattened apexes, exceeding to the base of gonostylus; the joint edge of dorsal and ventral valves rolled ventrad, with three acute teeth ventrally, and one long spine dorsolaterally (Fig. 2D-F).

Description of female. Similar to males in general appearance. The ocellar pattern more rounded than that of males; wings with pterostigmal band more developed (Fig. 1B). Forewing length $11.10 \pm 0.35 \mathrm{~mm}$, width $2.48 \pm 0.13 \mathrm{~mm}$; hindwing length $10.17 \pm 0.27 \mathrm{~mm}$, width $2.31 \pm 0.11 \mathrm{~mm}$, similar to forewings.

Female genitalia. A9 nearly twice the length of A8. Subgenital plate accompanied with two lateral plates, which slightly beyond half the length of the main part; main part with basal half trapezoid, distal half vase-shaped and bearing long thick setae marginally (Fig. 3A, B). Genital plate small, shorter than half of subgenital plate; axis 


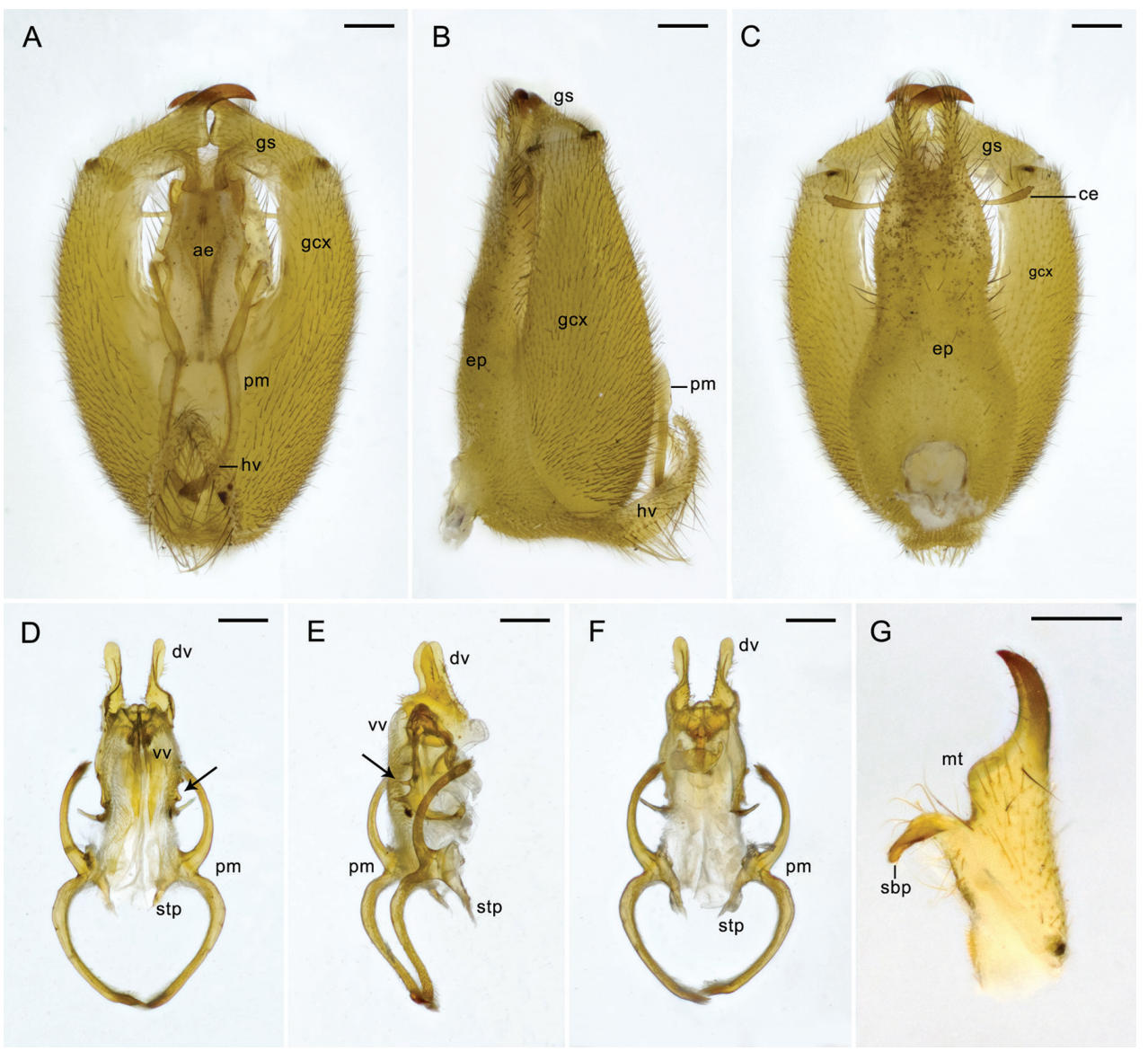

Figure 2. Male genitalia of Panorpa reflexa sp. n. A-C Genital bulb in ventral, lateral, and dorsal views D-F aedeagal complex in ventral, lateral, and dorsal views, arrows pointing to the teeth along the joint edges of dorsal and ventral aedeagal valves $\mathbf{G}$ gonostylus, dorsal view. ae aedeagus; ce cercus; $\mathbf{d v}$ dorsal valve; ep epandrium; gcx gonocoxite; gs gonostylus; hv hypovalve; $\mathbf{m t}$ median tooth; $\mathbf{p m}$ paramere; sbp subbasal process; stp stalk of paramere; vv ventral valve. Scale bars: $0.2 \mathrm{~mm}$.

short, entirely concealed in the main plate, posterior apex acute; anterior arms shorter than main plate, curved entad; posterior arms longer than main plate, straight, narrowed toward the apex, slightly convergent (Fig. 3C).

Etymology. The specific epithet is derived from the Latin reflex- (turned back, reflected), referring to the anterior arms of the paramere in male genitalia being reflected, and not directed caudad as usual.

Distribution. China (Yunnan Province).

Comparisons. Panorpa reflexa sp. n. is similar to P. decolorata Chou \& Wang, 1981 from Shaanxi Province, P. filina Chou \& Wang, 1987 from Hunan Province, $P$. waongkehzengi Navás, 1935 from Jiangxi Province, China in abdominal morphology, but differs from the latter three species by the males of $P$. reflexa with the paramere 


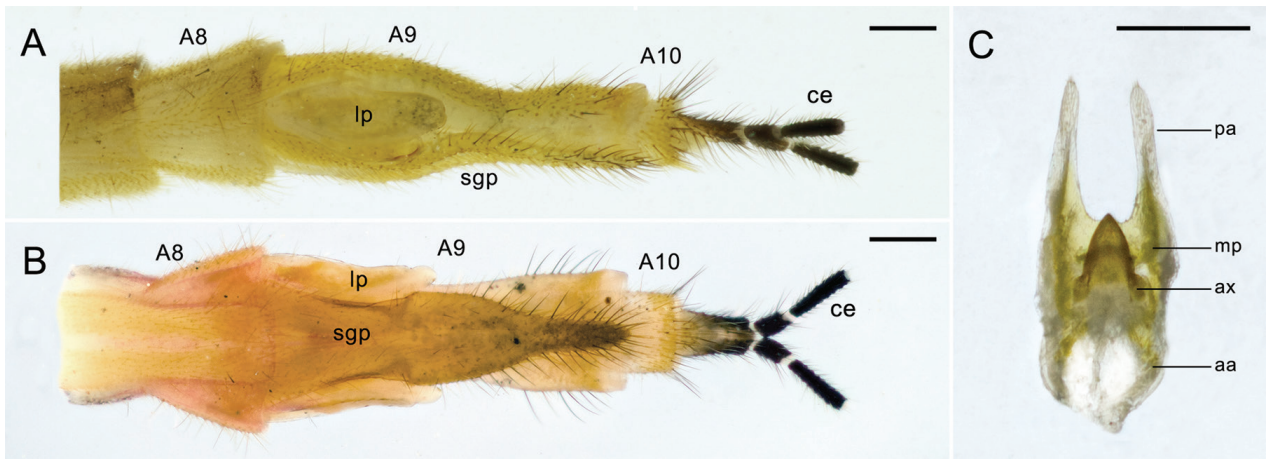

Figure 3. Female terminalia of Panorpa reflexa sp. n. A and B Terminalia in lateral and ventral views C genital plate, ventral view. aa anterior arm; ax axis; ce cercus; Ip lateral plate; $\mathbf{m p}$ main plate; pa posterior arm; sgp subgenital plate. Scale bars: $0.2 \mathrm{~mm}$.
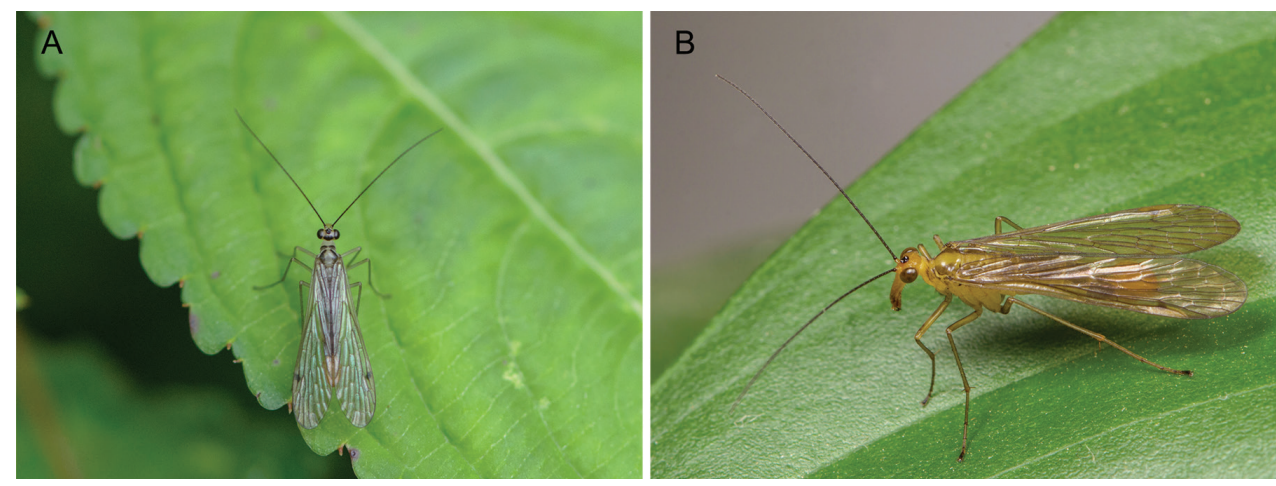

Figure 4. Male adults in the field. A Panorpa reflexa sp. n. B Panorpa parallela sp. n.

3-shaped and its anterior arm directed cephalad (cf. parameres are directed caudad, whether branched or not).

Panorpa reflexa resembles $P$. guttata Navás, 1908 from Sichuan Province, China in the greatly reduced pterostigmal band in wings, but can be easily distinguished from the latter by the black ocellar triangle and postvertex (cf. vertex is uniformly colored).

\section{Panorpa parallela sp. n.}

http://zoobank.org/243661E8-7438-4B26-B3C6-5D904B7CDBCD

Figs 4B, 5-7

Type material. Holotype: CHINA: Yunnan Province: $\widehat{\delta}$, Mt. Daxueshan [大雪山] $\left(24^{\circ} 11.27^{\prime} \mathrm{N}, 99^{\circ} 37.35^{\prime} \mathrm{E}\right), 2000 \mathrm{~m}$, Yongde County [永德县], 21 Aug. 2015, leg. Ji-

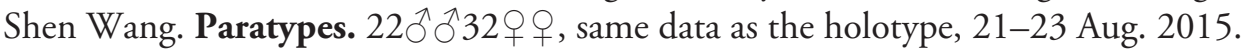

Diagnosis. This new species resembles $P$. reflexa sp. $\mathrm{n}$. in appearance, but can be readily differentiated from the latter by the following characters: 1) head yellowish 


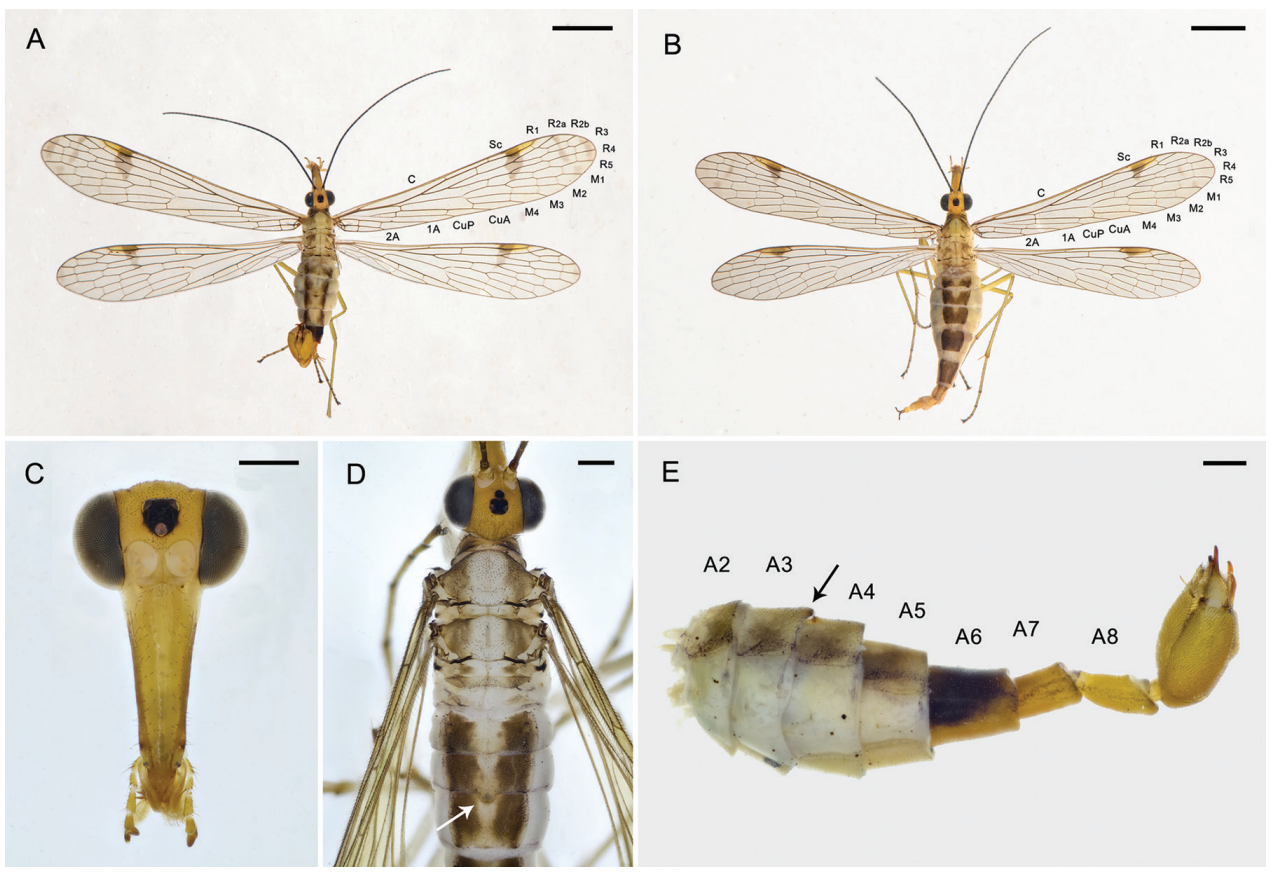

Figure 5. Adults of Panorpa parallela sp. n. A Habitus of male, dorsal view B habitus of female, dorsal view; $\mathbf{C}$ head of male with antennae removed, frontal view; $\mathbf{D}$ dorsum of male; $\mathbf{E}$ abdomen of male, lateral view. Arrows show the notal organ on tergum III. Scale bars: (A, B): $2.5 \mathrm{~mm}$; (C-E): $0.5 \mathrm{~mm}$.

brown, with ocellar triangle black (cf. head yellow with two black patterns, one on dorsum and the other one around ocellar triangle);2) forewing with a faint apical band (cf. apical band absent); 3) hypandrium with elongated basal stalk (cf. basal stalk extremely shortened); 4) parameres in male genitalia simple and protruding caudad, almost parallel (cf. 3-shaped).

Description of male. Head. Head muddy yellow with ocellar triangle black. Antennal socket light yellow, scape yellowish brown, pedicel dark brown, flagellum black and with 39-42 segments. Rostrum unevenly muddy yellow with genae pale, subgenae brown. Maxillary and labial palps yellowish brown with distal segments darkening toward the apex (Fig. 5C).

Thorax. Pronotum brown, bearing 4-6 stout setae along its anterior margin. Mesoand metanotum light brown with a broad yellowish longitudinal stripe and a faint brown mesal line (Fig. 5D). Pleura pale brown. Legs yellow, with distal tarsi deep brown.

Wings. Forewing length $10.81 \pm 0.51 \mathrm{~mm}$, width $2.37 \pm 0.10 \mathrm{~mm}$, membrane hyaline, pterostigma reddish brown with dense microtrichia. Pterostigmal band brown, reduced to an irregular spot with acute hind apex, extending to vein $R_{2+3}$, even to $M_{1}$ in some individuals. Apical band faint, degenerated as two irregular stripes, very faint in a few individuals. Vein $1 \mathrm{~A}$ ending almost at the level of the origin of Rs. Hindwing length $9.98 \pm 0.40 \mathrm{~mm}$, width $2.19 \pm 0.08 \mathrm{~mm}$, similar to forewings but pterostigmal band and apical band more degenerated (Fig. 5A). 


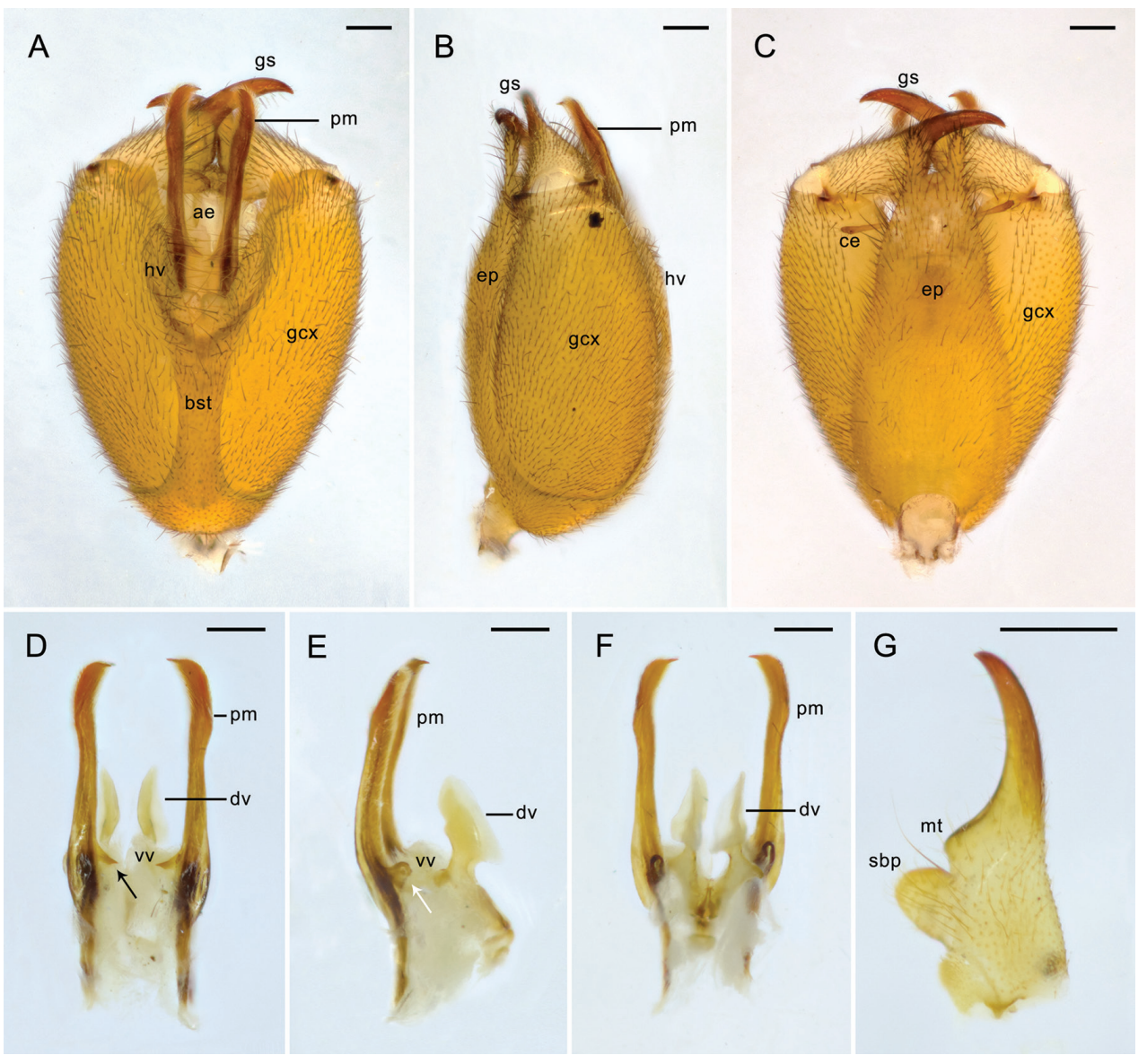

Figure 6. Male genitalia of Panorpa parallela sp. n. A-C Genital bulb in ventral, lateral, and dorsal views D-F aedeagal complex in ventral, lateral, and dorsal views, black and white arrows show the inner teeth and dorsal process of paramere, respectively $\mathbf{G}$ gonostylus, ventral view. ae aedeagus; bst basal stalk of hypandrium; ce cercus; dv dorsal valve; ep epandrium; gcx gonocoxite; gs gonostylus; hv hypovalve; $\mathbf{m t}$ median tooth; $\mathbf{p m}$, paramere; sbp subbasal process; vv ventral valve. Scale bars: $0.2 \mathrm{~mm}$.

Abdomen. Terga I-V sordidly brown, with a yellowish longitudinal mesal stripe, which is weakened and forms several continuous or discontinuous triangular spots at each tergum; pleura pale, sterna light brown. Notal organ on the posterior margin of tergum III slightly developed, covering the acute dorsal process of tergum IV (Fig. 5D). A6 dark brown dorsally and yellowish ventrally, without anal horns. A7 and A8 yellowish orange, with some faint brown textures along lateral surfaces; A7 cylindrical, A8 constricted basally and beveled apically (Fig. 5E).

Male genitalia. Genital bulb yellowish orange, oval (Fig. 6A-C). Epandrium (tergum IX) extending beyond the apex of gonocoxite, broad basally and tapering toward the apex, with a deep U-shaped terminal emargination (Fig. 6C). Cerci brown. Hypandrium (sternum IX) Y-shaped, with a narrow elongated basal stalk and splitting into 


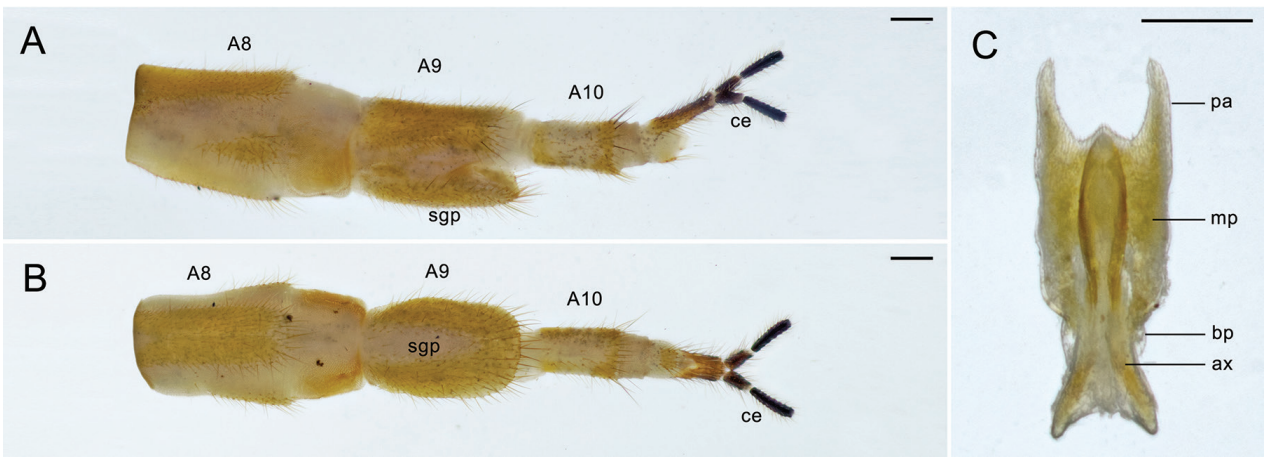

Figure 7. Female terminalia of Panorpa parallela sp. n. A, B Terminalia in lateral and ventral views; C genital plate, ventral view. ax axis; bp basal plate; ce cercus; $\mathbf{m p}$ main plate; pa posterior arm; sgp subgenital plate. Scale bars: $0.2 \mathrm{~mm}$.

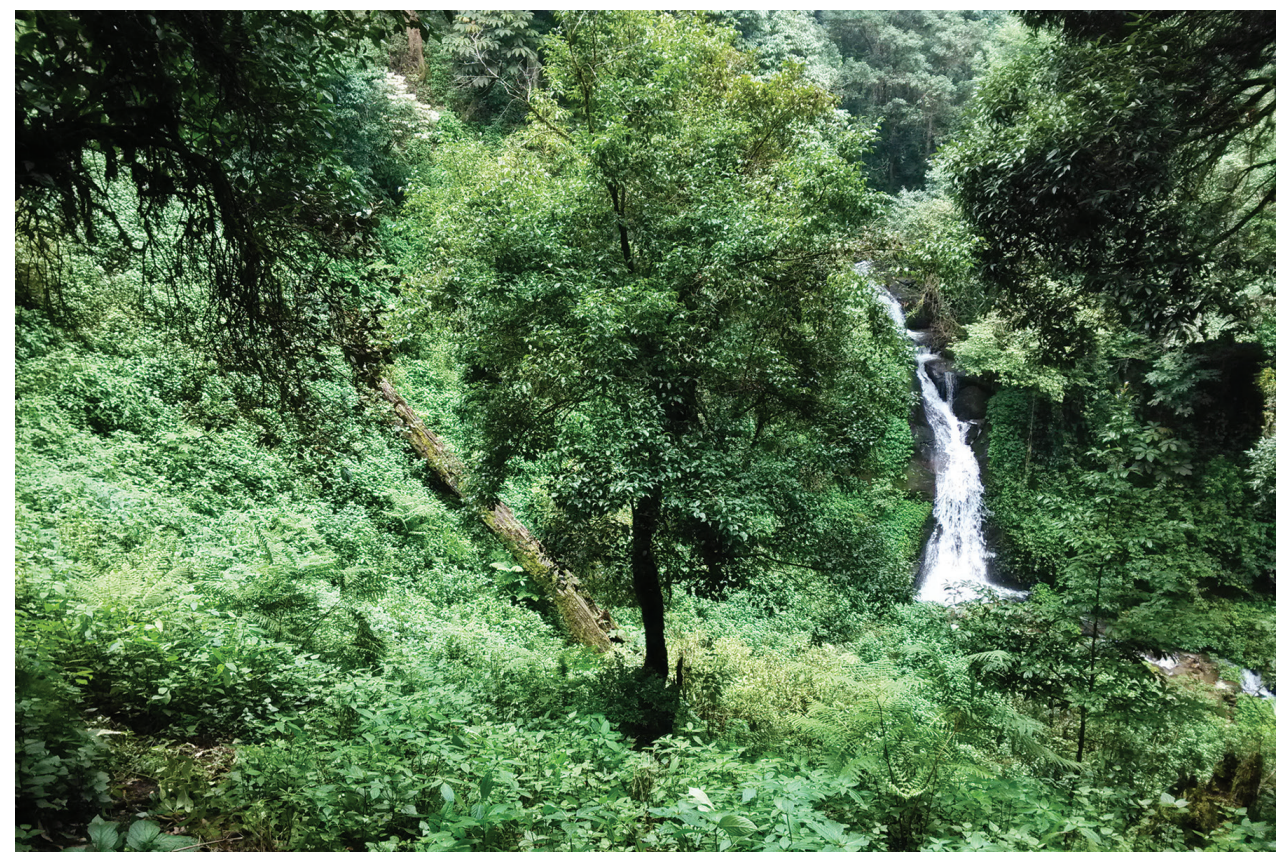

Figure 8. Habitat of the type locality.

paired hypovalves distally, extending to four-fifths of gonocoxite (Fig. 6A). Posteroventral margin of gonocoxite with a flat triangular process. Gonostylus slightly concaved along outer margin, inner margin with a blunt median tooth and an oval subbasal process, a long bristle rising between them (Fig. 6G). Parameres reddish brown, stick-like, extending far beyond the median tooth of gonostylus, approximately parallel, apexes acute and curved convergently, distal third with numerous microtrichia; inner margin with a pointed tooth subbasally, dorsal margin with a flat process next to the subbasal tooth (Fig. 6D-F). Ventral valves of aedeagus poorly developed, membra- 
nous; dorsal valves sclerotized, separated, with thin neck-like stalks, distal parts swollen and flatiron-shaped (Fig. 6D-F), extending nearly to the base of gonostylus.

Description of female. Similar to males in coloration and patterns (Fig. 5B). Forewing length $11.72 \pm 0.41 \mathrm{~mm}$, width $2.58 \pm 0.15 \mathrm{~mm}$; hindwing length $10.76 \pm$ $0.52 \mathrm{~mm}$, width $2.33 \pm 0.15 \mathrm{~mm}$, similar to forewings.

Female genitalia. A9 slightly shorter than A8. Subgenital plate long elliptic (Fig. 7A, B). Genital plate with main plate oblong and intensely constricted at base, posterior margin with a triangular mesal prominence; basal plate slightly wider than axis but narrower than main plate; axis elongated beyond the main plate, anterior third divergent widely, posterior third long elliptic with an acute apex; posterior arms almost half the length as main plate, broad basally and narrowed toward the apex, almost parallel (Fig. 7C).

Etymology. The specific epithet is derived from the Latin parallel- (parallel), referring to the parallel parameres in male genitalia.

Distribution. China (Yunnan Province).

Comparisons. Panorpa parallela sp. n. is similar to P. rufostigma Westwood, 1842 from Europe in the reddish pterostigma, but can be recognized by its greatly reduced wing markings (cf. wing markings well-developed).

Panorpa parallela resembles P. chengi Chou, 1981 from Shaanxi Province, China in body coloration, especially the pale-brown thoracic terga, but can be differentiated from the latter by the reddish pterostigma and the wing pattern (cf. pterostigma indistinct, wings devoid of markings).

The two new species, $P$. reflexa and $P$. parallela, resemble each other in general appearance at first glance. In living animals, the wings are held in close contact along the mid-line over the abdomen, and in the same plane at repose (Fig. 4). This condition is different for most species of Panorpa, the wings of which are mostly divergent and kept in a $\mathrm{V}$-shape over the abdomen at repose.

Habitat. In the type locality, Mount Daxueshan, these two species share the same habitat among several mountain valleys with streams around an elevation of 2000 m. Suitable microhabitats lie mostly in a slope surrounded by evergreen broad-leaved forests and with dense herbaceous groundcover (Fig. 8). In the daytime of August, these valleys are mostly overspread with mist, receiving little direct sunlight, and the temperature ranges approximately from 16 to $22{ }^{\circ} \mathrm{C}$.

\section{Acknowledgements}

We thank Sheng Dong, Yong Zhao, Ou Yang and Wen-Ping Yang of the Daxueshan National Nature Reserve for their assistance in our field surveys. Special thanks go to Victor Benno Meyer-Rochow for linguistic support, and two anonymous referees for valuable comments and suggestions in the revision of the manuscript. This research was financially supported by the National Natural Science Foundation of China (grant no. 31172125). 


\section{References}

Bicha W, Schiff N, Lancaster A, Scheffler B (2015) A nearly cryptic Scorpionfly, Panorpa cryptica n. sp. (Mecoptera: Panorpidae) from North America. Zootaxa 3973: 591-600. doi: 10.11646/ zootaxa.3973.3.12

Byers GW (1970) New and little known Chinese Mecoptera. Journal of the Kansas Entomological Society 43: 383-394.

Byers GW (2002a) Scorpionflies, hangingflies, and other Mecoptera. The Kansas School Naturalist 48: 252-258.

Byers GW (2002b) Mecoptera from Taiwan. Journal of the Kansas Entomological Society 75: 252-258.

Byers GW, Thornhill R (1983) Biology of the Mecoptera. Annual Review of Entomology 28: 203-228. doi: 10.1146/annurev.en.28.010183.001223

Cai LJ, Huang PY, Hua BZ (2008) Sinopanorpa, a new genus of Panorpidae (Mecoptera) from the Oriental China with descriptions of two new species. Zootaxa 1941: 43-54.

Carpenter FM (1945) Panorpidae from China (Mecoptera). Psyche 52: 70-78. doi: $10.1155 / 1945 / 69797$

Cheng FY (1957) Revision of the Chinese Mecoptera. Bulletin of the Museum of Comparative Zoology at Harvard College 116: 1-117.

Chou I, Ran RB, Wang SM (1981) Studies on the classification of Chinese Mecoptera (I, II). Entomotaxonomia 3: 1-18.

Esben-Petersen P (1921) Mecoptera. Monographic revision: Collections Zoologiques du Baron Edm. de Selys Longchamps. Catalogue Systematique et Descriptif 5: 1-172.

Fu Q, Hua BZ (2009) A new species of Panorpa (Mecoptera: Panorpidae) from Yunnan, China. Entomotaxonomia 31: 201-205.

Hu GL, Yan G, Xu H, Hua BZ (2015) Molecular phylogeny of Panorpidae (Insecta: Mecoptera) based on mitochondrial and nuclear genes. Molecular Phylogenetics and Evolution 85: 22-31. doi: 10.1016/j.ympev.2015.01.009

Ma N, Hua BZ (2011a) Structural evidence why males of Panorpa liui offer prey rather than salivary mass as their nuptial gift. Acta Zoologica 92: 398-403. doi: 10.1111/j.14636395.2010.00474.x

Ma N, Hua BZ (2011b) Furcatopanorpa, a new genus of Panorpidae (Mecoptera) from China. Journal of Natural History 45: 2251-2261. doi: 10.1080/00222933.2011.595517

Ma N, Liu SY, Hua BZ (2011) Morphological diversity of male salivary glands in Panorpidae (Mecoptera). European Journal of Entomology 108: 493-499. doi: 10.14411/eje.2011.064

Ma N, Zhong W, Gao QH, Hua BZ (2012) Female genital plate diversity and phylogenetic analyses of East Asian Panorpidae (Mecoptera). Systematics and Biodiversity 10: 159-178. doi: 10.1080/14772000.2012.683459

Misof B, Erpenbeck D, Sauer KP (2000) Mitochondrial gene fragments suggest paraphyly of the genus Panorpa (Mecoptera, Panorpidae). Molecular Phylogenetics and Evolution 17: 76-84. doi: 10.1006/mpev.2000.0817

Yang YM, Tian K, Hao JM, Pei SJ, Yang YX (2004) Biodiversity and biodiversity conservation in Yunnan, China. Biodiversity and Conservation 13: 813-826. doi: 10.1023/B:BIOC.000001 $1728.46362 .3 \mathrm{c}$ 
Zhang JX, Hua BZ (2012) A new species of the genus Panorpa from the Daba Mountains of central China. Entomotaxonomia 34: 541-547.

Zhong W, Hua BZ (2013a) Mating behaviour and copulatory mechanism in the scorpionfly Neopanorpa longiprocessa (Mecoptera: Panorpidae). PLoS ONE 8: e74781. doi: 10.1371/ journal.pone.0074781

Zhong W, Hua BZ (2013b) Dicerapanorpa, a new genus of East Asian Panorpidae (Insecta: Mecoptera: Panorpidae) with descriptions of two new species. Journal of Natural History 47: 1019-1046. doi: 10.1080/00222933.2012.752540

Zhong W, Ding G, Hua BZ (2015a) The role of male's anal horns in copulation of a scorpionfly. Journal of Zoology 295: 170-177. doi: 10.1111/jzo.12194

Zhong W, Qi ZY, Hua BZ (2015b) Atypical mating in a scorpionfly without a notal organ. Contributions to Zoology 84: 305-315. 